\title{
KONSEP LOKAL TENTANG PERAWATAN PAYUDARA DI DESA KENDAGA KECAMATAN BANJARMANGU KABUPATEN BANJARNEGARA
}

\author{
Barni $^{1)}$, Dewie Sulistyorini ${ }^{2}$ \\ ${ }^{1}$ bernibanjar@yahoo.co.id, ${ }^{2}$ dewiesulistyorini@gmail.com \\ ${ }^{1}$ Prodi D3 Kesehatan Lingkungan Politeknik Banjarnegara \\ J1. Raya Madukara KM 02, Kenteng, Banjarnegara 53482 \\ ${ }^{2}$ Prodi D3 Kebidanan Politeknik Banjarnegara \\ Jl. Raya Madukara KM 02, Kenteng, Banjarnegara 53482
}

\begin{abstract}
Abstrak
Setiap perempuan memiliki kodrat untuk menyusui namun tidak setiap orang memiliki produktivitas ASI yang sama. Perawatan payudara merupakan salah satu faktor penentu produksi ASI. Berbagai upaya dilakukan pemerintah untuk mensosialisasikan pentingnya perawatan payudara dengan cara yang benar. Perawatan payudara yang tepat saat kehamilan menentukan kelancaran ASI pada saat nifas. Setiap masyarakat memiliki konsep lokal atau pengetahuan lokal, perilaku, kepercayaan, tradisi dan pola budaya yang berbeda-beda. Penelitian ini bertujuan untuk mengungkap konsep lokal model perawatan payudara saat kehamilan dan saat nifas. Konsep lokal berkaitan dengan perawatan payudara dapat dijadikan entry point untuk meningkatkan program pemberian ASI dari sudut pandang masyarakat penerima progam. Penelitian ini menggunakan metode deskriptif kualitatif dan dilakukan di Desa Kendaga Kecamatan Banjarmangu Kabupaten Banjarnegara dengan melibatkan 11 informan. Hasil penelitian menunjukkan bahwa perawatan payudara baik pada masa kehamilan maupun pada masa nifas ada yang selaras dengan program dan ada yang belum selaras dengan harapan program. Sosialisasi secara berkelanjutan tentang perawatan payudara dapat meningkatkan pemahaman tentang perawatan payudara secara utuh.
\end{abstract}

Kata kunci : perawatan payudara, air susu ibu, kehamilan, nifas

\begin{abstract}
Every woman have nature to breastfeeding, however not everyone have same productivity breas milk. Breast care is one of the determining factors breas milk. Various goverment efforts to socializationthe importance of breast care in the right way. Proper breast care when pregnancy determine smoothness when post partum. Everyone have local concept or local kwonledge, behavior, trus, tradisoin and different cultures. Purposes of this research to revealed local concept of methode breast care when pregnancy and post partum. Local concept related with breast care can be entry point to improve giving breast milk program from point of view of the recipient community. Methode of this researchu use qualitative descriptive at Kendaga district, Banjarnegara sub district Banjarnegara with 11 respondent. The result of this research shows than rigth way breasth care when pregnancy or post partum some are in harmony and some are not harmony with program expectations. Continuous socialization about breast care can improve knowledge about breast care in full.
\end{abstract}

Keywords: Breast care, Breas milk, Pregnancy, Post partum

\section{Pendahuluan}

Setiap anak yang lahir ke dunia berhak mendapatkan ASI (Air Susu Ibu) terbaik dari ibunya. Pemberian ASI kelak akan berpengaruh pada tumbuh kembang seorang individu. ASI adalah susu yang diproduksi seorang ibu untuk konsumsi bayi dan merupakan sumber gizi utama bagi bayi yang belum dapat mencerna makanan padat ${ }^{[1]}$. Faktanya di masyarakat tidak semua ibu mampu memberikan ASI terbaiknya. Pada perempuan yang baru melahirkan tidak semuanya dapat memproduksi ASI 
dengan maksimal sehingga bayinya diberi susu formula sebagai pengganti ASI. Ada beberapa faktor yang mempengaruhi kelancaran produksi ASI antara lain: 1) Makanan, 2) Ketenangan jiwa dan fikiran, 3) Penggunaan alat kontrasepsi, 4) Perawatan payudara, 5) Anatomis buah dada, 6) Fisiologi, 7) Faktor istirahat, 8) Faktor isapan anak, dan 9) Faktor obat-obatan khusunya obat-obatan yang mempengaruhi hormon prolaktin dan oxytocin yang berfungsi dalam pembentukan dan pengeluaran $\mathrm{ASI}^{[2]}$.

Perawatan payudara merupakan salah satu faktor penentu kelancaran ASI disamping faktor lainnya. Payudara adalah organ vital untuk memproduksi ASI pada perempuan pasca melahirkan oleh karena itu perlu dilakukan perawatan dengan maksimal. Perawatan payudara yang benar dapat melancar sirkulasi darah dan mencegah penyumbatan pada saluran susu. Fakta lain di masyarakat, masih pula dijumpai ibu nifas yang mengeluhkan kesulitan saat menyusui disebabkan karena anatomi payudara yang memiliki puting terlalu kecil. Permasalahan tersebut sebenarnya dapat diminimalisir jika pada saat hamil mulai melakukan perawatan payudara ${ }^{[3]}$.

Beberapa kajian tentang perawatan payudara yang telah dilakukan menunjukkan bahwa pengetahuan tentang perawatan payudara memiliki pengaruh yang signifikan terhadap kelancaran produksi ASI pada ibu post partum $^{[4]}$. Penelitian lain menunjukkan bahwa praktek budaya tertentu masih kuat diyakini mempengaruhi payudara. Sebagai contoh, praktek budaya Suku Kampung Yepase Jayapura, mengungkapkan bahwa terdapat larangan perilaku pada ibu nifas untuk bepergian karena berisiko diikuti roh jahat yang dapat berdampak pada kehilangan payudara atau payudara mengempes ${ }^{[5]}$. Berbeda dengan penelitian kesehatan pada umumnya, penelitian ini fokus pada konsep lokal tentang perawatan payudara. Setiap masyarakat memiliki konsep lokal atau pengetahuan lokal, perilaku, kepercayaan, tradisi dan pola budaya yang berbeda-beda. Konsep lokal itulah yang sering dikesampingkan program akibatnya timbul kegagalan program kesehatan. Kajian dilakukan pada ibuibu menyusui di Desa Kendaga Kecamatan Banjarmangu Kabupaten Banjarnegara dengan mendasarkan pada pengetahuan atau kognitif masyarakat dari sudut pandang penerima program yang berupa gagasan, kepercayaan dan pengetahuan ${ }^{[6]}$. Bahwa mengkaji kebudayaan berati mengkaji kognitif atau pengetahuan masyarakat. Kajian ini bertujuan untuk menemukan persamaan dan perbedaan pengetahuan antara masyarakat dan pembawa program tentang perawatan payudara sehingga dapat dijadikan entry point untuk meningkatkan program pemberian ASI. Pemahaman masyarakat yang belum selaras dengan harapan program, maka dapat diluruskan agar sesuai dengan perkembangan pengetahuan kesehatan saat ini.

\section{Metode Penelitian}

Penelitian ini dilakukan dengan metode deskriptif kualitatif dan pendekatan Antropologi Kesehatan. Penelitian dilakukan di Desa Kendaga Kecamatan Banjarmangu Kabupaten Banjarnegara dengan melibatkan 11 informan yang seluruhnya adalah ibuibu yang masih menyusui. Proses pengumpulan data dilakukan dengan metode partisipasi observasi dan wawancara secara mendalam. Analisis data dilakukan melalui tahap reduksi data (data reduction), tahap sajian data (data display) dan tahap pengambilan kesimpulan/verifikasi data dengan melibatkan peneliti dalam proses interpretasi; penetapan makna dari data yang tersaji (Denzin dan Lincoln, $2009)^{[7]}$.

\section{Hasil dan Pembahasan}

a. Sumber Informasi Perawatan
Payudara

Perawatan payudara merupakan suatu tindakan sadar yang bertujuan 
untuk memelihara kesehatan payudara baik dilakukan sendiri maupun dibantu orang lain yang umumnya dilakukan mulai dari hari pertama atau kedua pasca melahirkan (Rosanah, 2015). Informan di Desa Kendaga dalam melakukan perawatan payudara ada yang dilakukan mandiri dan ada yang dilakukan dengan melibatkan bantuan dukun bayi seperti disampaikan informan sebagai berikut:

“....kalau saya dulu, mbah dukun memijat tubuh saya termasuk payudara, katanya biar susunya lancar tidak macet apalagi baru anak ke satu katanya begitu....." (informan 1).

Dukun bayi di pedesaan masih berperan dalam perawatan ibu dan bayi sebelum dan sesudah melahirkan. penelitian Barni dan Munfiah (2014) tentang Perspektif Masyarakat terhadap Dukun bayi dan Bidan, bahwa dukun bayi memiliki peran utama pasca melahirkan seperti memijat ibu, membantu memandikan bayi, memijat bayi dan sebagainya. Salah satu peran utama dukun bayi adalah membantu perawatan payudara dengan teknik pijat maupun menggunakan ramuan-ramuan. Disamping informasi dari dukun bayi, informasi tentang perawatan payudara yang selaras dengan nasehat dukun bayi juga disampaikan dari orang tua (ibu) kepada anaknya $^{[8,9]}$.

Kegiatan posyandu dan kelas ibu hamil masih aktif diselenggarakan sebagai media sosialisasi. Dalam kegiatan tersebut masyarakat dapat memperoleh berbagai informasi kesehatan. Informasi tentang perawatan payudara juga diperoleh dari tenaga kesehatan. Sejumlah informan menyampaikan bahwa petugas kesehatan atau bidan pada kegiatan posyandu maupun kelas ibu hamil menginformasikan berbagai hal tentang perawatan payudara agar ASI lancar. Informan berikut menyampaikan sebagai berikut:

“...saya pernah datang ke posyandu juga ke kelas ibu hamil disana diajari banyak banget diajari $B u$ Bidan kalau pingin lancar ASInya payudaranya dirawat biar bersih seha, waktu hamil pas mandi puting ditarik-tarik dibersihkan..." (Informan 3)

Informasi-informasi tentang perawatan payudara yang telah sampai pada masyarakat baik bersifat medis modern yang dibawa oleh bidan maupun medis tradisional yang dibawa oleh dukun bayi atau yang telah ada di masyarakat sejak dahulu menjadi pengetahuan masyarakat. Berbagai informasi tersebut diterima masyarakat dan dijadikan pedoman dalam melakukan perawatan payudara. Pada keadaan ini memungkinkan masyarakat akan mengambil sebagian saja dari bentuk perawatan payudara yang dianggap masuk akal atau sesuai keinginannya. Inilah yang menurut Sairin (2002) adalah keadaan transisi yaitu nether here and nor there. Masyarakat terletak diantara (between) dua sistem, yakni medis modern dan medis tradisional dalam perawatan payudara $^{[10]}$.

b. Model Perawatan Payudara

Secara garis besar pemahaman masyarakat Desa Kendaga tentang perawatan payudara dapat diklasifikasikan menjadi dua yaitu perawatan payudara saat kehamilan dan perawatan payudara pada masa menyusui khususnya pada masa nifas.

1) Perawatan Payudara pada Masa Kehamilan

Pada saat perempuan mengalami masa kehamilan maka terjadi perubahan bentuk payudara, seiring dengan perubahan tersebut maka perlu ditingkatkan cara perawatannya. Kesadaran perempuan untuk melakukan perawatan payudara 
pada saat hamil masih rendah, hal tersebut terlihat dari sedikitnya gambaran perawatan yang dilakukan informan. Kondisi demikian sesuai dengan hasil penelitian Harahap (2007), menunjukkan tindakan dalam melakukan perawatan payudara selama kehamilan masih banyak yang belum melakukan perawatan payudara yaitu sebanyak 31 orang ( $67,4 \%)$. Perawatan payudara pada masa kehamilan biasanya dilakukan sejak memasuki usia kehamilan 8 bulan. Perawatan dilakukan mandiri dan adapula yang dilakukan dengan bantuan dukun bayi. Berikut pengalaman tiga informan tentang hal tersebut: “...saya pas hamil anak ke satu, setelah mandi payudara ditarik taraik putingnya biar menjol jadi saat menyusui mudah, pas anak ke dua sudah tidak perlu lagi karena sudah menonjol tinggal dibilas dengan air biasa atau air hangat..." (informan 4).

".....pernah pijat ada dua kali pada waktu hamil, mbah dukun juga memijat badan juga payudara saya katanya agar saat lahiran langsung lancar, sedikit dipencet sudah mulai keluar airnya atau belum istilahnya mengetes saja...." (informan 5)

"...pada waktu mandi, ini kan rambut saya panjang, ujungnya saya tusukkan diputing kata orang dulu buat lubang, sekitar saat hamil delapan bulanan saya lakukan itu....." (informan 6)

Pengalaman informan ke 4 menunjukkan salah satu teknik merawat payudara pada masa kehamilan dilakukan mandiri khusunya pada kelahiran anak ke satu. Sedangkan informan ke 5 menyatakan bahwa teknik pijat juga menjadi bagian dari bentuk perawatan payudara pada masa kehamilan. Informan 6 menyatakan bahwa teknik perawatan yang dilakukan bersumber dari cerita generasi sebelumnya, meskipun hal ini jarang didengar dari informan lain namun informan 6 tersebut masih mempraktekkannya ${ }^{[11]}$.

Metode perawatan payudara pada masa kehamilan meliputi beberapa persiapan yang perlu dilakukan untuk memperlancar pengeluaran ASI adalah:

a) Membersihkan puting susu dengan air atau minyak, sehingga epitel yang lepas tidak menumpuk.

b) Puting susu diterik setiap mandi, sehingga menonjol untuk memudahkan isapan bayi.

c) Bila puting susu belum menonjol, dapat menggunakan pompa susu atau dengan jalan operasi $^{[12]}$.

Bentuk perawatan payudara yang dilakukan masyarakat pada masa kehamilan sebagian besar masih selaras dengan model perawatan yang diharapkan dari program kesehatan, antara lain 1). puting payudara dibersihkan dengan air hangat atau air dingin pada saat mandi, 2). puting ditarik-tarik khusunya bagi yang putingnya tidak menonjol. Pengalaman informan 3 bahwa pemijatan payudara diperlukan dalam perawatan payudara pada masa kehamilan juga belum ditemukkan kajian lebih lanjut. Sedangkan pengalaman informan 6 tentang caranya merawat payudara dengan rambut tidak ditemukan dalam konsep medis modern. Bentuk perawatan seperti itu kontras dengan batasanbatasan tentang perawatan payudara dari petugas kesehatan. Adapun sumber informasi teknik tersebut adalah dari generasi sebelumnya dan diwariskan. Sedikitnya pemahaman perawatan payudara seperti yang disampaikan informan 6 menunjukkan bahwa teknik 
tersebut tidak banyak dipilih oleh masyarakat dan lebih memilih anjuran petugas kesehatan.

2) Perawatan Payudara pada Masa Nifas

Perawatan payudara pada masa nifas selain dilakukan sendiri, melibatkan dukun bayi juga melibatkan kerabat dekat. Pola kehidupan masyarakat Jawa pedesaan menurut Koenjaraningrat (1994) sangat erat dalam kekerabatan yakni pada umumnya orang Jawa berhubungan dengan keluarga inti, saudara kandung dan anakanaknya, kakek dan nenek, saudara ipar dan sebagainya Termasuk dalam hal perawatan payudara terdapat keterlibatan kakak perempuan atau ibu misalnya pada saat menyiapkan ramuan pelancar ASI, menyiapkan obat-obatan pada saat payudara bengkak dan sebagainya. Pengalaman informan berikut ini menunjukkan hal tersebut:

".....wah tiga hari setelah melahirkan rasanya payudara besar kaku, ibu saya langsung mencarikan daun dadap ditumbuk dan dioleskan agar tidak panas lagi, mbak saya membeli ramuan pelancar...." (informan 7)

Dalam pengambilan keputusan perawatan medis apa yang akan dipilih, umumnya dilakukan oleh anggota-anggota kerabat dewasa dalam keluarga batih atau dalam lingkungan kekerabatan yang lebih luas, kawan-kawan dan tetangga. Keputusan bentuk perawatan payudara yang dipilih juga memperhatikan masukkan anggota keluarga lainnya. Padahal salah satu hambatan sosial budaya terhadap suatu pembangunan kesehatan juga diantaranya adalah aspek kemasyarakatan khususnya dalam hal pengambilan keputusan $^{[13,14]}$.
Pada periode awal nifas, payudara seorang ibu belum tentu dapat langsung lancar untuk menyusui. Namun pengalaman ini tidak dapat disamakan karena setiap orang memiliki kemampuan menyusui yang berbeda-beda. ASI lancar umumnya terjadi pada kelahiran anak ke dua dan seterusnya dibandingkan saat anak pertama. Pada kelahiran anak ke dua secara pesikologis ibu lebih siap menjalankan perannya kembali untuk menyusui. Hasil penelitian Avilia, Widjanarko dan Ratnaningsih (2013) menunjukkan bahwa semakin banyak jumlah paritas maka dapat mempengaruhi hasil pengetahuan, sikap dan praktek ibu terhadap perawatan payudara. Pengalamanpengalaman sebelumnya saat menyusui dapat dijadikan pengetahuan untuk mengatasi permasalahan yang dihadapi yakni sebanyak 60\% ibu nifas yang diteliti memiliki pengetahuan baik ${ }^{[14]}$.

Keadaan yang sering dialami informan pada kelahiran anak pertama ASInya belum lancar dua sampai tiga hari, oleh karena itu banyak yang bayinya diberi susu formula. Upaya yang dilakukan informan untuk memperlancar ASI pada masa nifas adalah memijat payudara yang dilakukan dukun bayi, dan meminum ramuan. Dukun bayi akan memberikan sejumlah saran dan pemijatan. Pada hari ke tiga dukun bayi akan "memeriksa/ mengecek" payudara apakah sudah menghasilkan ASI dengan lancar atau belum disamping memijat seluruh tubuh yang dalam istilah lokalnya bregudug / lulur. Adapun untuk memeriksa produktivitas ASI, dilakukan dengan memijat pelan payudara dan memencet puting susu hingga keluar ASInya sedikit. Jika 
setelah diperiksa dianggap belum lancar maka dukun bayi biasanya memberikan jamu yang diracik sendiri, maupun jamu yang dibeli di pasar seperti jamu Jong Rahab. Berikut pengalaman informan 8: “.......Sepulangnya dari Rumah sakit, dukun bayi datang memijat tangan dan kaki juga payudara diusap atau diuyeg. Mbah dukun hanya mengetes pas tiga harinya, mbah dukun seperti hanya mengecek sudah lancar atau belum itu saja, karena belum lancar saya dikasih jamu untuk diminum sampai ASI nya lancar..."(informan 8)

Pengalaman informan di atas, secara medis dapat dijelaskan bahwa pada hari ke tiga pasca melahirkan barulah ASI lancar. Dalam buku Asuhan Kebidanan Nifas, disebutkan bahwa pada hari kedua atau ketiga pasca persalinan, kadar estrogen dan progresteron durun drastis, sehingga pengaruh prolaktin lebih dominan dan pada saat inilah mulai terjadi sekresi ASI sehingga hari ke tiga ASI baru lancar. Pengalaman perawatan payudara setiap informan berbeda-beda tergantung dengan jenis permasalahan yang dihadapi apakah payudara mengalami nyeri, lecet, bengkak, atau abses pada masa nifas. Bentuk perawatan payudara secara umum yaitu dengan mengupayakan agar tangan dan puting susu tetap bersih, jangan mengoleskan krim, minyak, alkohol dan sabun pada puting susu. Meskipun ibu mengalami puting susu nyeri, lecet, bengkak, mestitis atau abses payudara (Ambarwati dan Wulandari, 2008). Permasalahan tersebut secara rinci penangannannya dapat dijelaskan sebagai berikut:

a) Puting susu nyeri:
(1). Pastikan posisi menyusui benar

(2). Mulailah menyusui pada puting susu yang tidak sakit.

(3). Segera setelah minum, oleskan asi pada puting sampai mengering.

b) Puting susu lecet:

(1). Cari penyebabnya

(2). Olesi puting susu dengan ASI

(3). Puting susu yang sakit diistirahatkan sementara waktu, namun ASI dikeluarkan dengan tangan.

(4). Cuci payudara sekali sehari jangan menggunakan sabun

(5). Bila tidak sembuh dalam satu minggu, rujuk ke puskesmas

c) Payudara bengkak:

(1). Kompres panas

(2). Ibu rileks

(3). Pijat leher, punggung, dan payudara dengan pelan

(4). Kompres dingin setelah menyusui

(5). Menggunakan BH yang sesuai

(6). Bila terlalu sakit dapat diberi obat analgetik

d) Mestitis atau Abses Payudara / peradangan pada payudara:

(1). Kompres hangat/panas dan pemijatan.

(2). Stimulasi puting susu, pijat leher punggung

(3). Pemberian antibiotik

(4). Istirahat total dan minum obat penghilang rasa sakit

(5). Tidak disusukan jika memerlukan tindakan bedah. ${ }^{[16]}$

Bentuk perawatan payudara yang dilakukan informan pasca melahirkan / nifas beragam tergantung keadaan yang dihadapinya, namun secara umum telah selaras dengan harapan program. Berikut pengalaman 
informan 9 dan 10 bahwa saat terjadi nyeri dan lecet maka dioleskan air susu hingga mengering.

".......ada sekitar satu minggu lebih puting saya lecet dan nyeri pokoknya sakit luar biasa takut menyusui, ada yang bilang katanya obatnya air susu dioleskan, saya telateni alhamdulilah sembuh tanpa harus ke dokter....."(informan 9)

".......saat menyusu pernah payudara nyeri karena ada sedikit lecet, saya oleskan air susu setiap sebelum dan sesudah menyusui dan sembuh...." (informan 10)

Demikian pula pengalaman informan 11 pada saat payudara bengkak dan abses selain dilakukan perawatan mandiri juga dibawa ke dokter. Selengkapnya informan 11 menyatakan sebagai berikut:

“......payudara pernah bengkak dan memerah besar dan terasa panas, saya sudah kompres dengan air hangat, dipijiat, dikasih daun dadap tidak juga sembuh lalu akhirnya ke dokter dikasih obat alhamdulillah sembuh...." (informan 11)

Tindakan informan dalam perawatan payudara seperti mengoleskan air susu, memijat, mengompres dengan air hangat dan saat gejala lebih lanjut pergi ke dokter sudah sesuai dengan anjuran pemerintah sebagaimana tertuang dalam Buku Kesehatan Ibu dan Anak Tahun 2015. Adapun informan yang menggunakan daun dadap (godong tawa) atau erytrina variegata saat payudara bengkak dengan cara menempelkan daun dadap yang telah ditumbuk tersebut pada payudara supaya terasa dingin belum ada sumber pustaka yang menerangkan khasiatnya dengan jelas. Demikian pula pemberian jamu tertentu dengan tujuan memperlancar ASI pada ibu menyusui juga perlu dikaji lebih lanjut. Model perawatan payudara yang telah dipahami masyarakat ada yang sejalan dan ada yang belum sejalan dengan harapan program kesehatan. Beragamnya sumber informasi medis modern dan medis tradisional yang diperoleh dan kepercayaan yang masih ada di masyarakat menyebabkan beragam pula teknik perawatan payudara yang dilakukan masyarakat. Dengan kata lain tradisi dan kepercayaan lokal yang dimiliki masyarakat mempengaruhi perilaku kesehatan. Hasil penelitian lain tentang ASI yang dilakukan Setyaningsih dan Farapti (2018) mengungkapkan bahwa ada hubungan kepercayaan dan tradisi keluarga mempengaruhi pemberian ASI esklusif. Tradisi dan kepercayaan yang kurang mendukung dapat menghambat keberhasilan pemberian ASI Esklusif. Konsep lokal tentang perawatan payudara maupun tentang pemberian ASI secara umum, sepanjang teknik yang dipraktekkan masyarakat tidak merugikan kesehatan maka dapat diabaikan dan sebaliknya jika merugikan kesehatan, maka perlu diluruska oleh petugas kesehatan $^{[16]}$.

\section{Kesimpulan}

Sumber informasi yang diperoleh informan tentang perawatan payudara berasal dari tenaga kesehatan / bidan, dukun bayi dan kerabat dekat. Pelaksanaan praktek perawatan payudara dapat dilakukan diri sendiri, dibantu dukun bayi maupun keluarga terdekat. Model perawatan payudara pada masa kehamilan dan pada masa nifas menunjukkan teknik yang beragam. Bentuk perawatan payudara yang dijalankan ada yang selaras dan ada yang belum selaras dengan harapan program kesehatan. Petugas kesehatan 
diharapkan melakukan sosialisasi tentang perawatan payudara secara utuh agar diperoleh pengetahuan yang utuh pula bagi masyarakat sasaran program.

\section{Ucapan Terima Kasih}

Peneliti mengucapkan terimakasih kepada Unit Penelitian dan Pengabdian kepada Masyarakat (UP2M) Politeknik Banjarnegara, Dinas Kesehatan Kabupaten Banjarnegara, dan Puskesmas Banjarmangu 2 serta Pemerintah desa Kendaga atas terselenggarakannya penelitian ini.

\section{Daftar Pustaka}

[1] Kodrat, L. Dahsyatnya ASI dan Laktasi. Yogyakarta: Media Baca. 2010.

[2] Kristiyani, W. ASI, Menyusui dan Sadari, Cetakan ke II. Yogyakarta: Nuha Medika. 2011.

[3] Maritalia, D. Asuhan Kebidanan, Nifas dan Menyusui. Yogyakarta : Nuha Medika. 2012.

[4] Mododahi, J., Katuuk, M., Kundre, R., Hubungan Pengetahuan Perawatan Payudara dengan kelancaran Produksi ASI pada Ibu Post Partum di Ruangan Dahlia RSD Liun Kandaghe Tahuna kabupaten Kepulauan Sangihe. Manado : Jurnal Keperawatan. 2018. 6 (10). Mei 2018. http://ejournal.unsrat.ac.id.

[5] Yufuai, A.R. dan Widagdo, L. Praktek Budaya Suku kampung Yepase terkait Perawatan Kehamilan, Nifas dan Bayi di Distrik Depapre kabupaten Jayapura. Semarang : Jurnal Promosi Kesehatan Indonesia. 2013. 8 (2). Agustus 2013. http://ejournal.undip.ac.id.

[6] Spradley, J.P. Metode Etnografi. Yogyakarta : Tiara Wacana. 2007.

[7] Denzin, N.K. dan Lincoln, Y.S. Manajemen Data dan Metode Analisis, Handbook of Qualitative Research.
Yogyakarta: Pustaka Pelajar. 2009.

[8] Rosanah, H.M. Ibadah Penuh Berkah Ketika Haid dan Nifas. Jakarta : Lebar langit Indonesia. 2015.

[9] Barni dan Munfiah. Perspektif Masyarakat terhadap Dukun Bayi dan Bidan dalam Persalinan di Kecamatan Banjarmangu Banjarnegara. (Suatu Kajian Antopologi Kesehatan). Laporan Penelitian. Banjarnegara : Politeknik Banjarnegara. 2014.

[10] Sairin, S. Perubahan Sosial Masyarakat Indonesia : Perspektif Antropologi. Yogyakarta : Pustaka Pelajar. 2002.

[11] Harahap, R. A.. Analisis Perilaku Ibu hamil dalam melakukan Perawatan Payudara di Klinik Khadijah Lupuk Pakam. Medan : Jurnal Jumantik. 2017. 2 (2); 52. http:// jurnal.unisu.ac.id.

[12] Saleha, S. Asuhan Kebidanan pada Masa Nifas. Jakarta : Salemba Medika. 2009.

[13] Koentjaraningrat. Kebudayaan Jawa. Jakarta : Balai Pustaka. 1994.

[14] Kalangie, N.S. Kebudayaan dan Kesehatan : Pengembangan Pelayanan Kesehatan Primer Melalui Pendekatan Sosial Budaya. Jakarta : Kesaint Blane. 1994.

[15] Avilia, O., Widjanarko, B., Ratnaningsih, E.. Deskripsi Pengetahuan, Sikap, dan Praktek Perawatan Payudara pada Ibu Nifas di Ruang Bougenville Rumah Sakit Panti Wilasa"Citarum" Semarang. Semarang: Jurnal Kebidanan Panti Wilasa. 2013. 4(1). Oktober 2013.

http://ejurnal.akbidpantiwilasa.ac. id.

[16] Setyaningsih, F.E.T., dan Farapti, F. Hubungan Kepercayaan dan Tradisi Keluarga pada Ibu Menyusui dengan Pemberian ASI 
Esklusif di Kelurahan Sidotopo,

Semampir, Jawa Timur. Surabaya

$$
\text { Jurnal Bioetika dan }
$$

Kependudukan. 2018. 7(2).

Desember 2018. http://ejournal.unair.ac.id. 